\title{
System for dynamic visualization of geomagnetic disturbances according to the data of ground magnetic stations
}

\author{
A. V. Vorobev',A,B, V. A. Pilipenko,,B,C, T. A. Enikeev3,A, G. R. Vorobeva4,A, \\ O.I. Khristodulo5,A \\ A Ufa State Aviation Technical University \\ B Geophysical Center of the RAS \\ C Institute of Physics of the Earth of the RAS \\ ${ }^{1}$ ORCID: 0000-0002-9680-5609, geomagnet@list.ru \\ 2 ORCID: oooo-0003-3056-7465, pilipenko va@mail.ru \\ 3 ORCID: oooo-0003-2184-3034, entagir@gmail.com \\ 4 ORCID: 0000-0001-7878-9724, gulnara.vorobeva@gmail.com \\ 5 ORCID: oooo-0002-3987-6582, o-hristodulo@mail.ru
}

\begin{abstract}
Due to the established and well-studied effects of the impact of the space environment on technical objects of high-latitude infrastructure, which are most clearly manifested during periods of magnetic storms, the problem of creating an effective open system for visualization and analytical control of geomagnetic field and its variations parameters, especially for the polar regions, is quite acute today.

In this paper, using data from magnetic observatories and variation stations included in the SuperMAG project (https://supermag.jhuapl.edu/), based on the Django framework, open web-based GIS platforms and libraries, an approach, the architecture, model and methods of the system of dynamic multiparameter $2 \mathrm{D} / 3 \mathrm{D}$ visualization of the disturbed component of geomagnetic field variations are suggested. In addition to the possibility of dynamic visualization, an important distinctive feature of the proposed system is that the investigated parameters can be represented both as isodynes, which are the isolines of the same intensity of the Earth's magnetic field, and as vectors that form a vector field, which as a result carries additional, and for some problems of geomagnetism - defining information about the dynamics, nature and structure of the distribution of geomagnetic disturbances over the Earth's surface. The beta version of the developed system is available at https://geomagnetic.ru/.
\end{abstract}

Keywords: geomagnetic field, geomagnetic variations, geographic information system, visualization of spatial data.

\section{Introduction}

The development of high-latitude areas of the Earth in general and the Arctic zone of the Russian Federation (AZRF) in particular is inevitably associated with solving problems related to the behavior and operation of complex technical objects in the physical conditions of the natural environment of this region. Increased, and sometimes extreme geomagnetic activity in the auroral and subauroral zones of the Northern Hemisphere is one of those factors, the neglect of which leads to a decrease in the overall level of technospheric safety in the polar regions and, as a result, accidents and technospheric disasters of various scales.

For example, a magnetic storm on March 13, 1989 caused the failure of power transformers and a cascade shutdown (or blackout) of power transmission lines (PTL) for 
more than 9 hours in the province of Quebec (Canada) [1]. In the united power system of the north-west of Russia in November 2001, due to geomagnetic activity, there were two times of one-way disconnection of the overhead transmission line $(330 \mathrm{kV})$ "OlenegorskMonchegorsk" from the substation "Olenegorsk", as a result of which consumers with a total capacity of more than $70 \mathrm{MW}$ were disconnected [2]. In October 2003, a similar cause resulted in a 20-50 minute power outage in the power system in Malmo in southern Sweden. From the report of "Zurich Insurance Group" it follows that in the United States alone, as a result of electrical failures during the periods of magnetic storms from 2005 to 2015, insurance payments exceeded $\$ 1.9$ billion [3].

In papers [4-5] it is noted that almost every strong magnetic storm is the cause of synchronous anomalies in the signal automation of the northern branches of the Oktyabrskaya (St. Petersburg - Murmansk) and Severnaya (Yaroslavl - Vorkuta) railways. In addition, the influence of space weather on technical objects during periods of magnetic storms is associated with magnetic dragging (damping of the angular velocity) of artificial satellites of the Earth, satellite anomalies [6]; violation of short-wave radio communications [7-8]; additional errors in underground navigation systems during directional drilling of wells [9], etc.

In turn, the necessary monitoring of geomagnetic field (GMF) parameters is carried out today mainly through several hundreds of ground magnetic stations connected in a network, which are (from the consumer's side) specialized web services that provide access to time series of geomagnetic data and have tools necessary to find, preview and download them [10]. However, type and format (usually CSV corresponding to the IAGA-2002 standard) of the data provided in this way do not provide an understanding of the properties of the spatial distribution of the observed parameters, which is necessary both in the tasks of predicting extreme geomagnetic activity and in preventing / minimizing its consequences.

Today the most popular results of research in this scientific area are concerned with the services INTERMAGNET (Fig. 1, a) and SuperMag (Fig. 1, b), which form a general characteristics of spatial distribution of the geomagnetic disturbances parameters. Along with this, the mentioned services from the leading providers of geomagnetic data do not actually provide the level of visualization that is required to identify the properties and structure of the regional distribution of geomagnetic parameters. So, for example, by means of these systems, due to their low resolution, it is not possible to distinguish impulse disturbances of GMF with a characteristic duration of 5-10 min, recorded at polar magnetic stations with an amplitude of more than $100 \mathrm{nT}$ in both horizontal and vertical components. In this case, the rate of change in the GMF parameters during such events can reach up to $30 \mathrm{nT} / \mathrm{s}$, which is many times higher than the variability of similar parameters during the Quebec event in 1989.

In addition, the lack of spatial interpolation, tools for express analysis and interface management (Fig. 1, a), as well as visualization results presentation in the form of a raster image loaded onto the page (Fig. 1, b) make the existing approaches ineffective and practically unsuitable for most geophysical (heliogeophysical) research, and in the tasks of creating an information environment for problem-oriented decision support systems (for example, in the field of technosphere safety). 


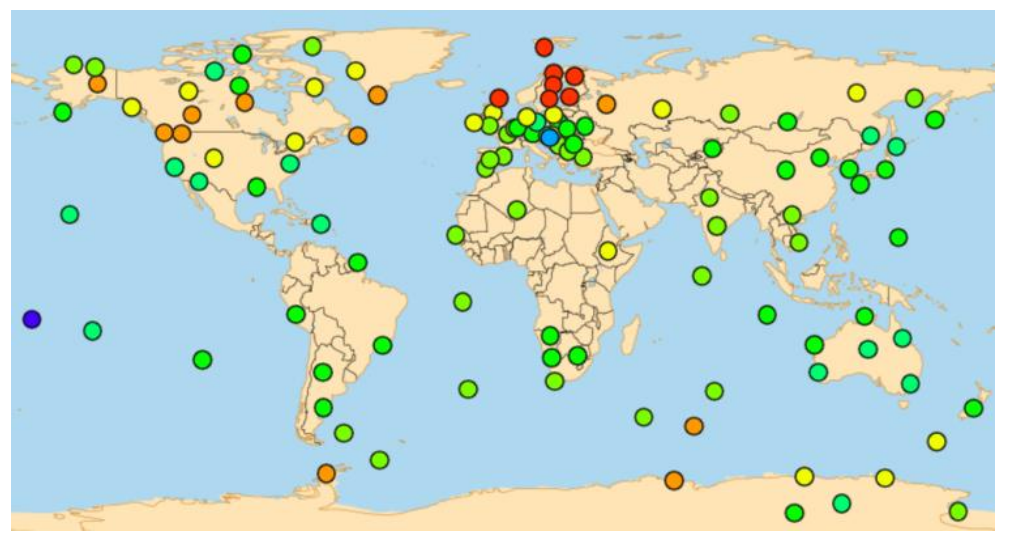

$a$

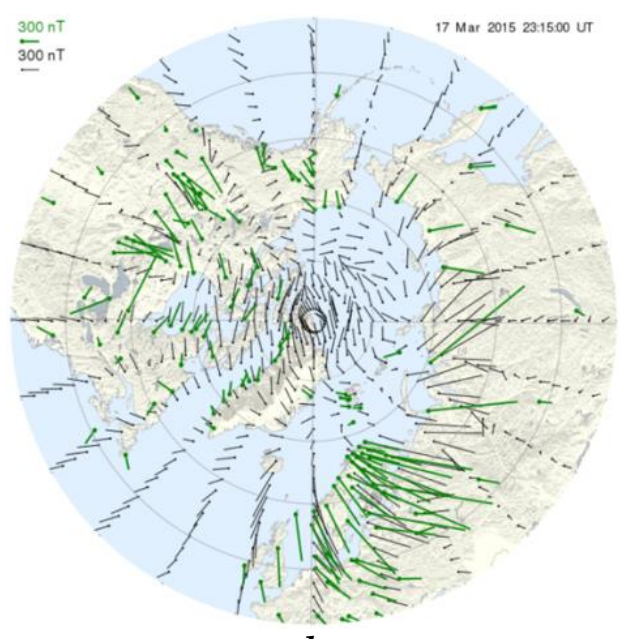

$b$

Fig. 1. Spatial visualization of geomagnetic variations based on data from ground stations (2015-03-17_23: 15 UT): a - full GMF vector (INTERMAGNET service: https://www.intermagnet.org/); b - horizontal component of GMF variations in the northern hemisphere (SuperMAG service: https://supermag.jhuapl.edu/)

Thus, the development of new, modernization and improvement of the efficiency of existing systems of analytical control and visualization of the extreme geomagnetic disturbances parameters (especially according to Decree of the President of the Russian Federation dated October 26, 2020 No. 645 "On the Strategy for the Development of the Arctic Zone of the Russian Federation and Ensuring National Security for the Period until 2035 "[11]) is an urgent scientific and technical problem with an acute applied character.

\section{Background}

Previously, in [12-14], the authors considered approaches and presented the results of web-based visualization of various kinds of geophysical parameters. For example, in [12], an approach to visualizing the IGRF model of the main geomagnetic field [15] was proposed and implemented, in [14] as a web-based approach to visualizing the position of the auroral oval based on the Ovation Prime model [16], etc.

However, the problem of visualizing geomagnetic disturbances based on data from ground-based magnetic stations initially supposes the spatial anisotropy of the data sources density, which is associated with rethinking and modernizing already proven techniques. In addition, a web-based mechanism for dynamic visualization of geomagnetic data is being developed and implemented, as well as a technique for their presentation in the form of a vector field.

\section{Initial data and their preliminary processing}

The research is based on geomagnetic data for 2015 (i.e., the period corresponding to the maximum activity of the 24th solar cycle (January 2009 - May 2020)) provided by the SuperMAG project (http://supermag.jhuapl.edu/), which is the international collaboration of leading scientific organizations engaged in fundamental research of terrestrial magnetism [17-18]. Here, the choice of the provider, in addition to the vast geomagnetic data base, is also based on the possibility of optional exclusion of the annual trend and diurnal variations from the time series, which is also provided by SuperMAG, as a result, allowing to significantly reduce the time spent on the development of the target resource and start preparing data for visualization directly from the formalization of one of the methods spatial interpolation.

So, for example, according to the Inverse Distance Weighting method, the interpolated value of a parameter at a given point in a geographic area is determined by the weighted 
average sum of deterministic values in its vicinity. In the case of Shepard's modification used in the research, the level of influence of the deterministic point on the value $X^{*}$ is set by the exponent $p$ and with distance from the top of the polygon, including the reference data sources, its influence on the interpolated value weakens. In other words, for the case under consideration, the analytical form of the IDW method in Shepard's modification can be defined as follows:

$$
X^{*}=\sum_{i=1}^{m} \frac{1}{d_{i}^{p}} X_{i} / \sum_{i=1}^{m} \frac{1}{d_{i}^{p}},
$$

where $m$ is the number of stations, $X_{i}$ is the value of the GMF parameter at the $i$-th station, $d$ is the distance between the studied point and the $i$-th station; $p$ is the weighting factor (in this research, $p=2.5$ ).

Further, in order to increase the informativeness of visualization, it makes sense to divide the available values (including interpolated ones) by quasi-logarithmic ranges (Table 1) so that the density isodynams within each of them under conditions of spatial anisotropy, which is especially manifested during periods of magnetic storms, was equal, or at least comparable. Classification of ranges in Table 1 is given in accordance with the expected effect of the impact of geomagnetic variations on technical objects and systems.

Table 1 - Scale of ranges of values of GMF vector disturbed variations

\begin{tabular}{|c|c|c|c|c|c|}
\hline \multicolumn{2}{|c|}{$\begin{array}{c}\text { Weak disturbance: } \\
\text { green-yellow gradient }\end{array}$} & \multicolumn{2}{c|}{$\begin{array}{c}\text { Moderate indignation: } \\
\text { yellow-red gradient }\end{array}$} & \multicolumn{2}{c|}{$\begin{array}{c}\text { Strong disturbance: } \\
\text { red-black gradient }\end{array}$} \\
\hline$[\mathrm{nT}]$ & {$[\mathrm{nT} / \mathrm{min}]$} & {$[\mathrm{nT}]$} & {$[\mathrm{nT} / \mathrm{min}]$} & {$[\mathrm{nT}]$} & {$[\mathrm{nT} / \mathrm{min}]$} \\
\hline$|N|<200$ & $|d N / d t|<50$ & $200<|N|<1000$ & $0<|d N / d t|<400$ & $|N|>1000$ & $|d N / d t|>400$ \\
\hline$|E|<400$ & $|d E / d t|<100$ & $400<|E|<1600$ & $0<|d E / d t|<500$ & $|E|>1000$ & $|d E / d t|>500$ \\
\hline$|Z|<400$ & $|d Z / d t|<80$ & $400<|Z|<1800$ & $0<|d Z / \mathrm{dt}|<700$ & $|Z|>1000$ & $|d Z / d t|>700$ \\
\hline$F<200$ & $|d F / d t|<60$ & $200<F<900$ & $0<|d F / d t|<700$ & $F>1000$ & $|d F / d t|>700$ \\
\hline
\end{tabular}

Note: $N, E$ and $Z$ are the northern, eastern and vertical components of the GMF vector, respectively; $F$ - full vector $\left(F^{2}=N^{2}+E^{2}+Z^{2}\right)$

At the final stage of preprocessing, to the data generated and presented in this way, we will apply one of the methods for generating isolines on a uniform grid of values, for example, "Marching squares" [19].

\section{Comparative analysis of spatial data visualization tools}

In general, variations in GMF as an object of visualization represent a structured set of spatial and attributive data, processing and graphical interpretation of which, obviously, is advisable to implement using the web-based GIS technologies. The accumulated experience of building a web GIS for visualizing geophysical parameters, described in [10, 12-14, 20], showed the consistency of this software and tools for solving this type of problem.

So, according to the way of representing spatial data, modern GIS can be divided into classic flat maps and virtual globes. On the one hand, taking into account the predominantly high-latitude nature of the objects location, the obvious advantage of virtual globes is the quality of their visual perception, the preservation of the geometric similarity of the contours, the ratio of the areas of the Earth's surface and the absence of cartographic distortions of projections inherent in flat maps, especially in the polar regions. However, on the other hand, visualization algorithms based on classical cartographic substrates, as a rule, do not need hardware acceleration, that is, they are less demanding on computer performance and are able to provide a result within a significantly shorter time interval, which determines their efficiency in dynamic visualization problems at mid and low latitudes. Thus, when developing a visualization system, it makes sense to 
provide for the implementation of graphic models both in a cartographic format and on the basis of the "virtual globe" technology.

In addition, it should be noted that the rendering speed of the final image is largely determined by the resolution of the loaded layers. Taking into account the density of geomagnetic data sources distribution [17-18] over the Earth's surface, as well as the boundaries of the most interesting geospatial zones in terms of visualization (auroraral and subauroral zones, the Arctic zone of the Russian Federation, etc.), it was found that in order to achieve this goal, it is advisable to limit small-scale (from 1: 2,000,000 to 1: 10,000,000) cartographic substrates.

Table 2 compares the characteristics and capabilities of the main programming libraries that provide work with geospatial data at the web application level.

Table 2 - Current GIS-API

\begin{tabular}{|c|c|c|c|c|c|c|c|}
\hline \multirow[b]{2}{*}{ Название (URL) } & \multicolumn{3}{|c|}{$\begin{array}{c}\text { Programming } \\
\text { Languages Support }\end{array}$} & \multirow[b]{2}{*}{$\begin{array}{l}\text { Visualization } \\
\text { Mode }\end{array}$} & \multirow[b]{2}{*}{$\begin{array}{c}\text { Free } \\
\text { to } \\
\text { use }\end{array}$} & \multirow[b]{2}{*}{$\begin{array}{l}\text { Web } \\
\text { Access }\end{array}$} & \multirow[b]{2}{*}{$\begin{array}{l}\text { Hardware } \\
\text { acceleratione }\end{array}$} \\
\hline & JavaScript & Python & Java & & & & \\
\hline $\begin{array}{|ll|}\text { ArcGIS } & \text { API } \\
(\text { https://developers.arcgis.com/) } & \\
\end{array}$ & + & + & + & Map, Globe & $+^{*}$ & + & + \\
\hline $\begin{array}{l}\text { Bing Maps V8 Web Control } \\
\text { (https://www.microsoft.com/en- } \\
\text { us/maps/web/) } \\
\end{array}$ & + & - & - & Map & $+^{*}$ & + & - \\
\hline Cesium (https://cesium.com/) & + & - & - & Map, Globe & + & + & + \\
\hline Gio.js (https://giojs.org/) & + & - & - & Globe & + & + & + \\
\hline $\begin{array}{l}\text { Google } \quad \text { Maps } \\
\text { (https://developers.google.com/maps/apis- } \\
\text { by-platform) }\end{array}$ & + & - & - & Map, Globe & $+^{*}$ & + & - \\
\hline $\begin{array}{ll}\text { Leaflet } & \text { (https://leafletjs.com/reference- } \\
\text { 1.7.1.html) } & \\
\end{array}$ & + & - & - & Map & + & + & - \\
\hline $\begin{array}{lll}\text { NASA } & \text { World } & \text { Wind } \\
\text { (https://worldwind.arc.nasa.gov/) } & \\
\end{array}$ & + & - & + & Globe & + & + & + \\
\hline $\begin{array}{ll}\text { OpenGlobus } & \text { API } \\
\text { (https://www.openglobus.org/) } & \end{array}$ & + & - & - & Globe & + & + & + \\
\hline $\begin{array}{l}\text { OpenLayers } \\
\text { (https://openlayers.org/en/latest/apidoc/) }\end{array}$ & + & - & - & Map & + & + & - \\
\hline $\begin{array}{l}\text { WebGLEarth } \\
\text { (https://www.webglearth.com/) }\end{array}$ & + & - & - & Globe & + & + & + \\
\hline $\begin{array}{l}\text { WhirlyGlobe } \\
\text { (https://mousebird.github.io/WhirlyGlobe/) }\end{array}$ & + & - & - & $\begin{array}{l}\text { Map, } \\
\text { Globe }\end{array}$ & + & + & + \\
\hline $\begin{array}{ll}\text { Yandex } & \text { Maps } \\
\text { (https://yandex.ru/dev/maps/) } & \\
\end{array}$ & + & - & - & Map & $+^{*}$ & + & - \\
\hline
\end{tabular}

Note: * shareware (with restrictions on the number of requests per day)

As follows from Table 2, today there is a fairly wide range of platforms, on the basis of which it is possible to implement an approach to dynamic visualization of the spatial distribution of the parameters of geomagnetic disturbances.

Thus, to solve the problem in a first approximation (without imposing requirements for the interface, tools, input data, visualization quality, compatibility and the possibility of further development), any of the listed libraries can be used (mainly: ArcGIS API, Bing Maps V8 Web Control, Cesium, Google Maps Platform, Leaflet, NASA World Wind, or WebGL Earth). However, upon closer examination, given the possibility of flexible expansion by connecting third-party libraries and APIs based on open standards, the presence of an Open Source license and a set of methods for processing spatial data most 
adapted to the tasks being solved, it is proposed to implement the system based on the Leaflet and Cesium libraries.

\section{Architecture and programming methods of the visualization system}

It is proposed to use the traditional client-server architecture as a basis for the system developed as a web application (Fig. 2). The server component combines the data and business logic layers: the first of them is responsible for connecting to the data providers, and the second one is implemented for preprocessing the responses received from them. The client component, in turn, integrates spatial data visualization functions for the user, thus providing appropriate support for interactive interaction with the application through a set of user interface elements.

Let's consider the purpose and features of the data providers used in the proposed architecture. So, distributed web services behave as data providers, which, in accordance with various client-server interaction protocols, provide the ability for program and user clients to receive geomagnetic data in accordance with the specified spatial and time query parameters. Since not all data providers provide support for cross-domain requests and data transfer between providers and consumers (CORS - Cross-origin resource sharing), interaction with them is implemented exclusively on the server side of the application.

Since the main business logic of a web application is centered around the acquisition and processing of multidimensional spatial data, the main criterion for choosing a server-side scripting language has become the support of libraries for efficient processing and analysis of spatial data. Using the method of analyzing hierarchies, the Python programming language was distinguished, which, when used on the server side, provides operational processing of spatial data using dynamically linked software libraries. The choice of the programming language clarifies the client-server architecture of the web application, dictated, among other things, by the requirements of the Django framework.

The specificity of this framework and, as a consequence, the architecture of the developed web application is the separation of the visual presentation and business logic of the application by means of the MVC (Model - View - Controller) programming pattern. At the same time, this pattern in relation to Django is redefined as the MVT (Model - View Template) format, all components of which can be used separately, according to the principle of microservice architecture.

It is important to note that in the proposed architecture, the M (Model) component is actually removed from the final application structure. This decision is due to the fact that the database (in the traditional sense) is not used in the visualization system, and its functioning is ensured by means of information flows dynamically obtained from spatially distributed sources of geomagnetic data. Thus, there is no need to use additional data structures, and, consequently, the use of the corresponding components of the pattern.

Based on the tasks of the application, its main functionality is assigned to the views (V View). They process the HTTP(S) requests received from the client, implement the processing of the requested spatial data, and form an HTTP (S) response, which, when transmitted to the client side, defines a set of spatial data for subsequent rendering using user agents (browsers).

To process spatial data, including the processes of collecting it from providers using existing communication protocols, a number of specialized libraries are used on the server side of the application: Pandas, NumPy, etc. Some of them implement the establishment of a connection session with remote data providers (Pandas), others perform processing received information (Pandas, NumPy).

In addition, in the developed visualization system, the Pandas-based representation (V View) provides aggregation of data received from providers, their unification, preprocessing and forms the final result in the form of data array in GeoJSON format. The 
resulting dataset in GeoJSON format is sent to the client side for subsequent rendering by the user agent.

Client-side application scripts are represented by two types of modules, each of which provides its own version of the web rendering of a spatial image based on the GeoJSON data received from the server and implements elements of interactive interaction of the end user with them. In fact, one stream of data from the server response is interpreted on the client side depending on the rendering mode selected by the user (flat map or virtual globe).

As already noted, in this work, the "virtual globe" rendering mode is implemented on the basis of the Cesium platform, an open JavaScript library for creating three-dimensional globes and maps in the high-precision WGS84 projection, which ensures highperformance interaction of the application with users.

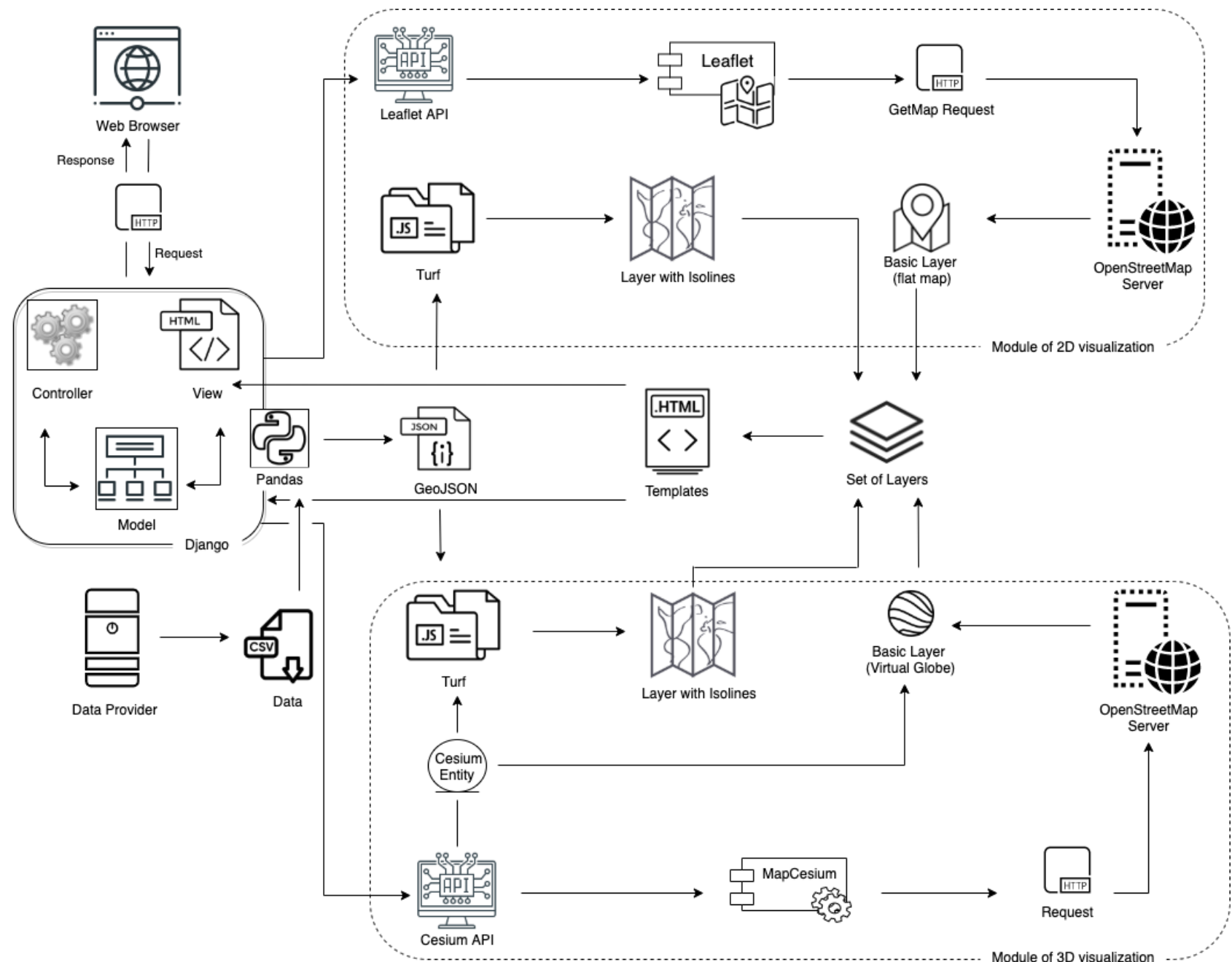

Fig. 2. Client-server architecture of the system (web application) for dynamic visualization of geomagnetic field disturbances based on data from ground-based magnetic stations

So, using the Cesium API, the set of JSON data presented in the server response is integrated into a single object - the Cesium Entity. Interaction with the Cesium Entity instance, in turn, is done through the Entity API library, which provides data-driven rendering techniques. It is in the context of a Cesium Entity instance that a set of high-level objects and their methods that combine data and a mechanism for their visualization into a single information structure. Entity API for manipulating Cesium Entity applies various heuristics to server-supplied data in response to provide flexible, high-performance webbased visualization of spatial data, while providing a logical programming interface. 
The formation of a visual representation of a spatial image within a web application is directly implemented through the MapCesium class developed on the basis of the Cesium API. With its implementation, in particular, at the initial stage of web rendering, an instance of the Cesium-class "Viewer" is created, which is responsible for drawing the virtual globe. To make the latter more realistic, a spatial layer is placed on top of the globe, which is obtained by requesting an instance of the class to the OpenStreetMap map server. As a result, the basis of the spatial image is formed - the so-called basic layer.

At the final stage, the created layers are combined - a layer with contours is superimposed on the basic layer and the final representation of the virtual globe with the spatial distribution of geomagnetic parameters is formed (Fig. 3, a).

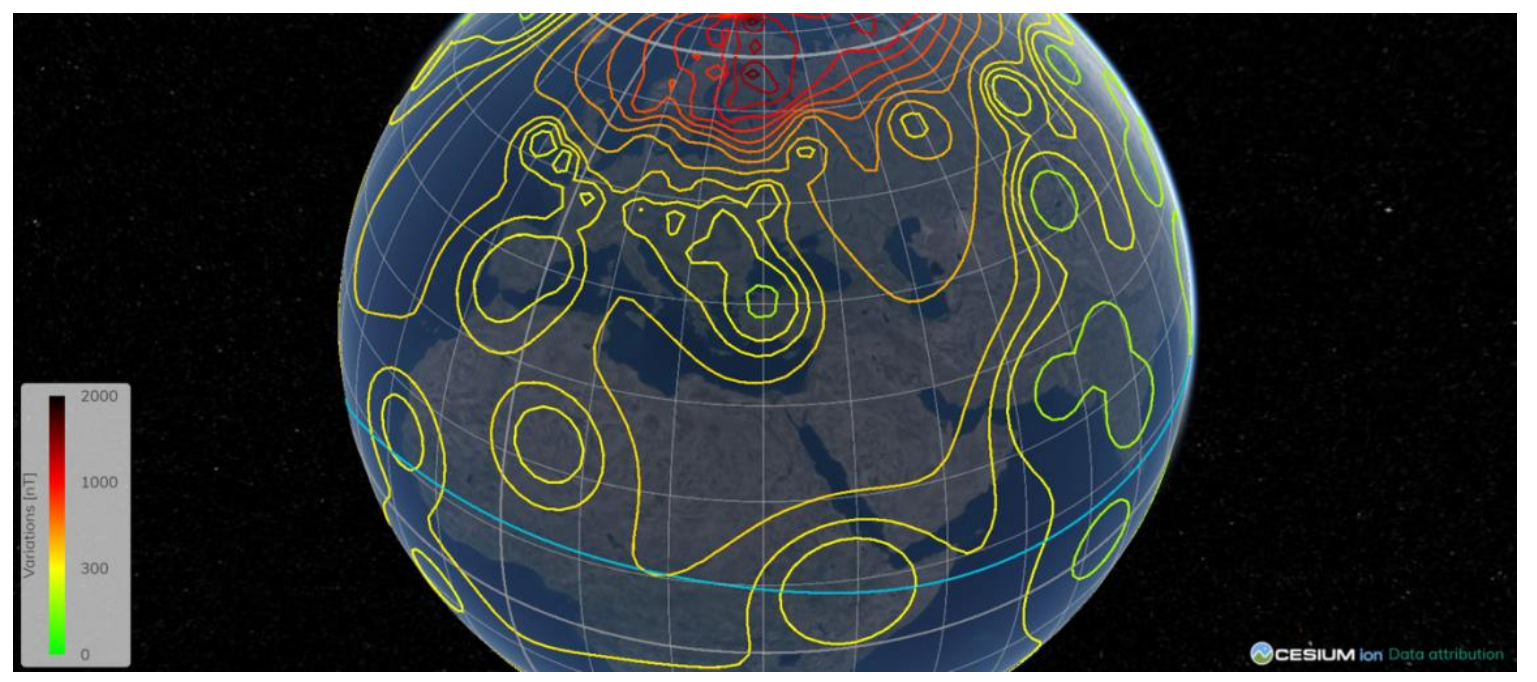

$a$

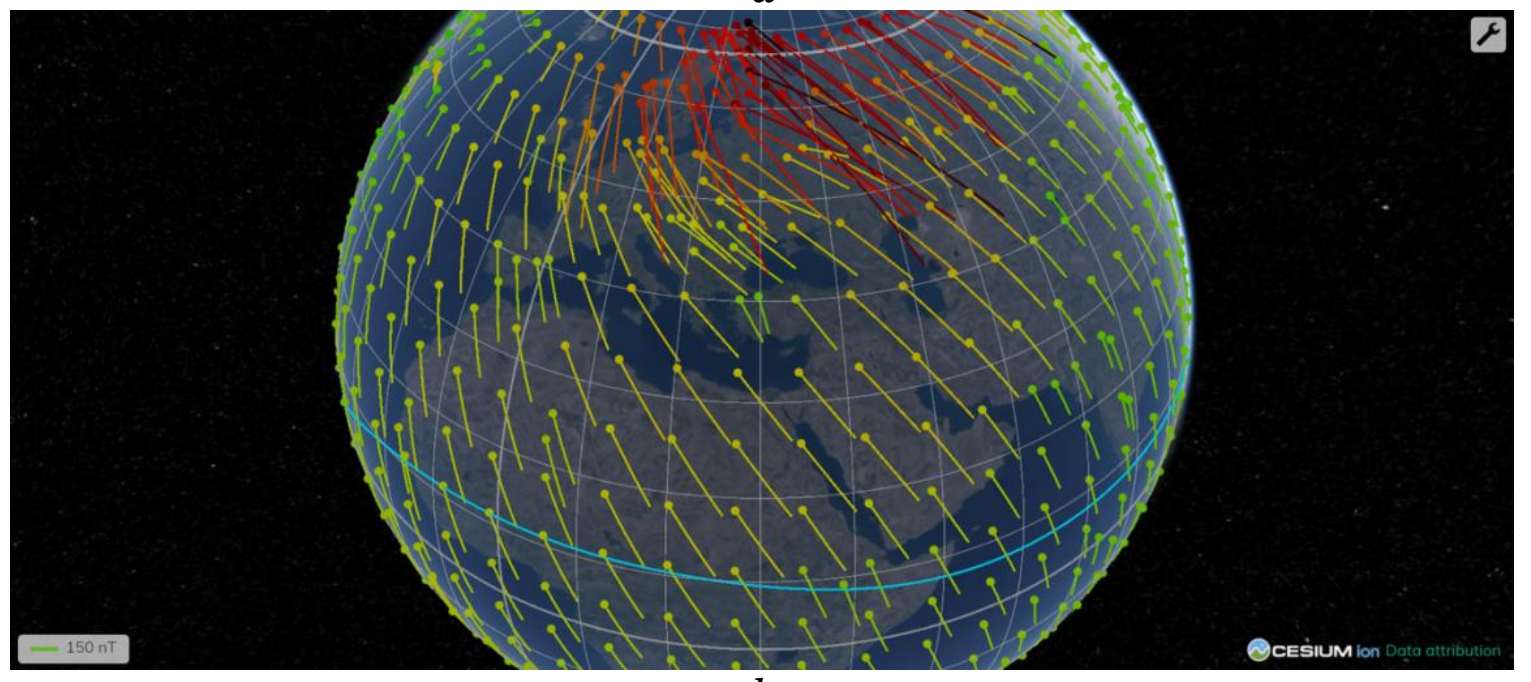

$b$

Fig. 3. Result of visualization of a magnetic storm fragment 2015-03-17 (23:15 UT) on the basis of a virtual globe in the form of isodynams (a) and a vector field in the horizontal plane (b)

(The magnetic equator is marked with a blue line)

The solution to the same problem, but with visualization on a flat map, is provided by another module of the web application, which is responsible for two-dimensional visualization of spatial data. The module is based on the Leaflet open source lightweight JS library, which allows processing spatial data in accordance with open network mapping protocols. At the initial stage, the base layer is formed by sending a request to the OpenStreetMap server by an instance of the Leaflet class or a map tile server (Web Map Tile Service). The Leaflet class provides not only obtaining basic map information from a 
remote server, but also rendering this data in a user's browser window in a deviceindependent mode.

Analytical processing of spatial data is implemented using the open source JS library Turf that allows a user to analyze, aggregate and transform spatial data on the client side at the web browser level. So, the module of the Turf ("Interpolate") library provides the construction of a solid surface with a given grid step size based on the initial geomagnetic data, and module "Isolines" implements the formation of a layer of isodynams (Fig. 4, a).
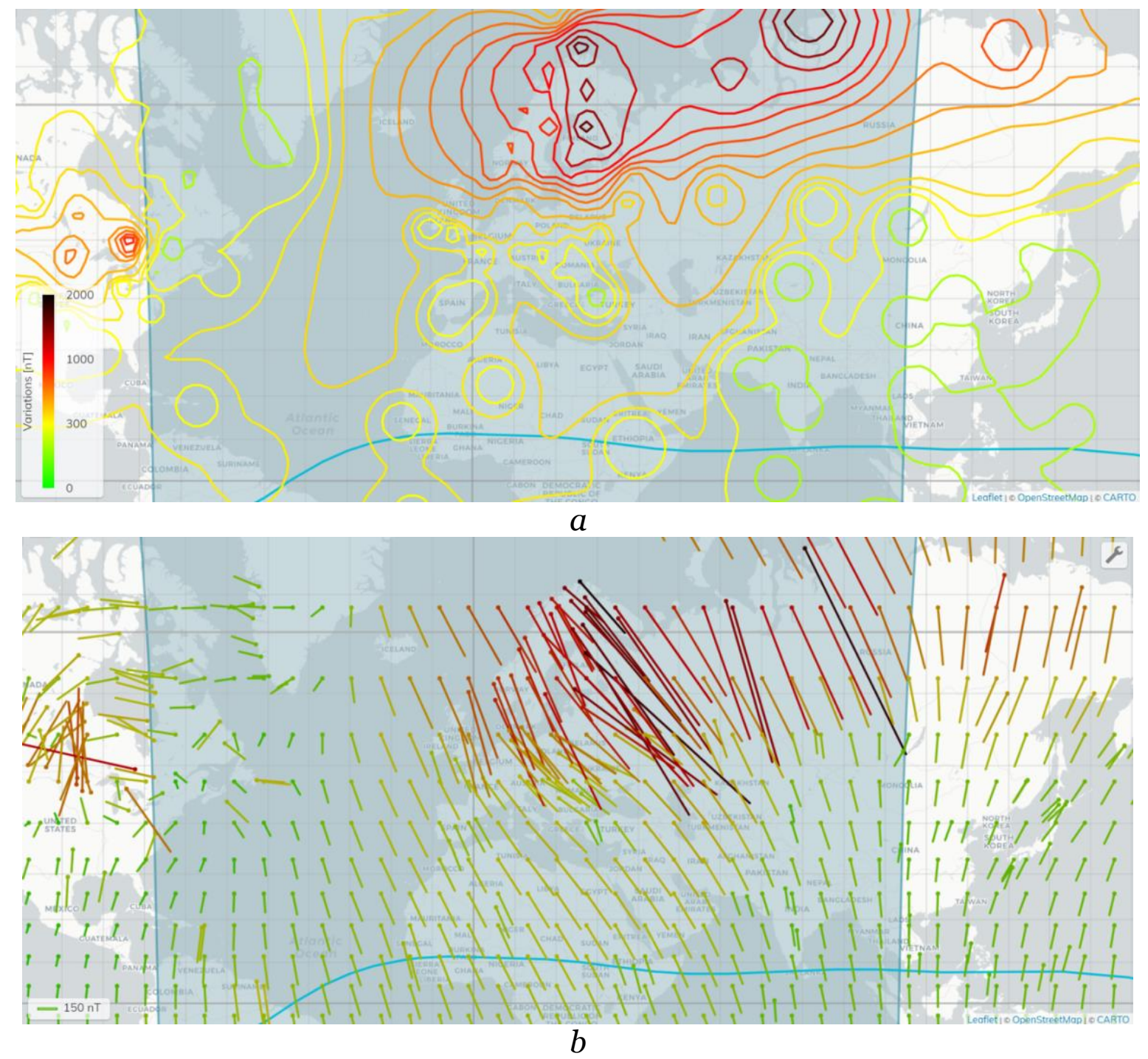

Fig. 4. Result of visualization of a magnetic storm fragment 2015-03-17 (23:15 UT) on the basis of a flat map in the form of isodynams (a) and a vector field in the horizontal plane

(b)

(The magnetic equator is marked with a blue line)

At the final stage (based on the methods of an instance of the Leaflet class), two generated spatial layers are integrated - the base layer and the contour layer.

Visualization of the spatial distribution of the GMF parameters in the form of a vector field (Fig. 3, b; Fig. 4, b) is implemented by forming (for each point) a polylinear layer representing geomagnetic data in the form of two-dimensional vectors in the horizontal plane based on the values of the northern and eastern components vectors:

$$
H=N+E \text {, }
$$

where $\mathrm{H}$ is a vector displayed in the horizontal plane; $\mathrm{N}$ and $\mathrm{E}$ are the northern and eastern components of the GMF vector, respectively. 
In the process of vector visualization of the H-component on the base layer of a virtual globe (Fig. 3, b) or a flat map (Fig. 4, b), the initial geographic coordinates of the measurement point are converted into a rectangular coordinate system relative to the user's browser window. Further, the values of the vector are incremented to the obtained coordinates, multiplied by the corresponding coefficient of proportionality. In this case, the value of the E-component of the GMF vector is added to the $\mathrm{x}$-coordinate, and the value of the $\mathrm{N}$-component is subtracted from the $\mathrm{y}$-coordinate. As a result, a set of coordinates of the end of the vector in a rectangular coordinate system is formed, which must be converted to geographic for spatial web rendering.

\section{Program formalization and discussion of results}

The described architecture and methods are formalized as a specialized web portal (https://geomagnetic.ru/), which includes a number of problem-oriented interactive services necessary for effective monitoring of geomagnetic disturbances.

So, Fig. 5 shows the screen form of the "Time Series" service, which provides manipulation operations with time series of heterogeneous geomagnetic data (components of the GMF variation vector, geomagnetic activity indices, substorm onset times, etc.), as well as providing tools for their visual display.

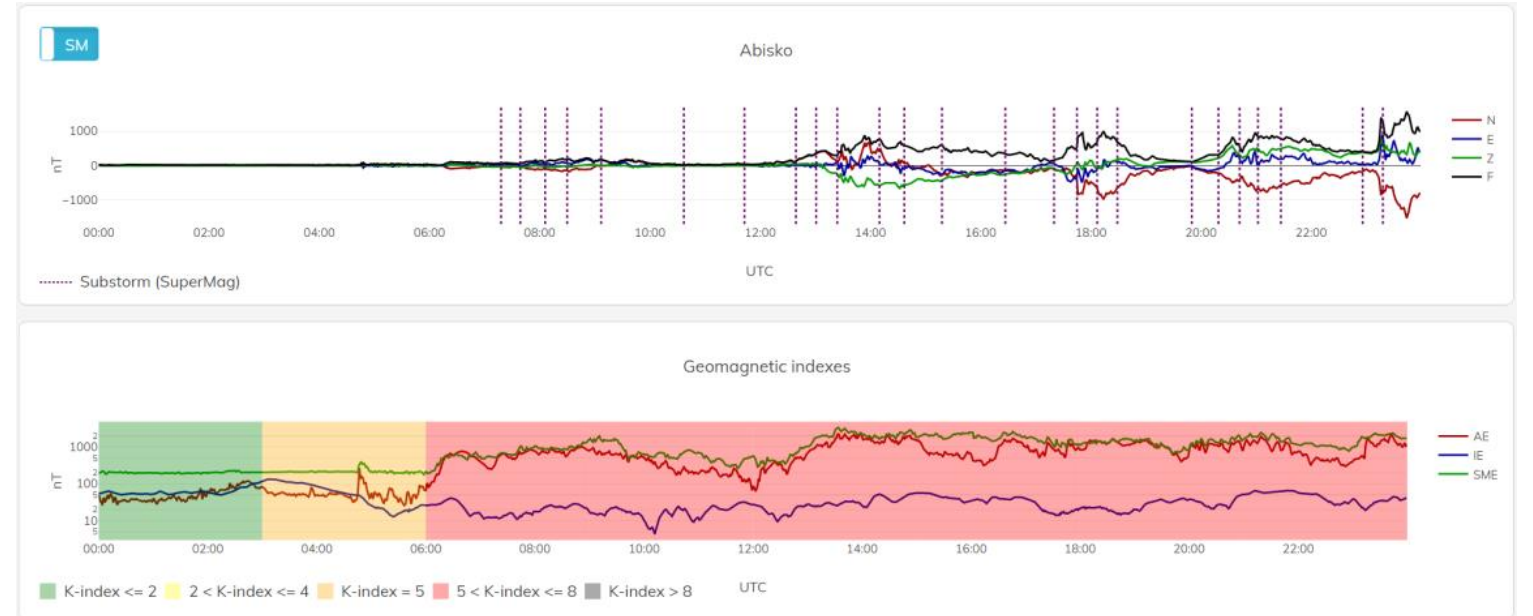

Fig. 5. Visualization of GMF disturbances recorded by the "Abisko" ABK station for March 17, 2015 (top) and a number of geomagnetic activity indices (bottom)

The "GeoSpatial" service visualizes the spatial distribution of GMF parameters depending on user settings based on a virtual globe (Fig. 3) or flat map (Fig. 4) in the form of isodynams or a vector field, as well as through sequential synthesis and rendering of layers provides a dynamic visualization (Fig. 6), which makes it possible to assess the nature of the global change in the parameters of the GMF not only in space, but also in time.

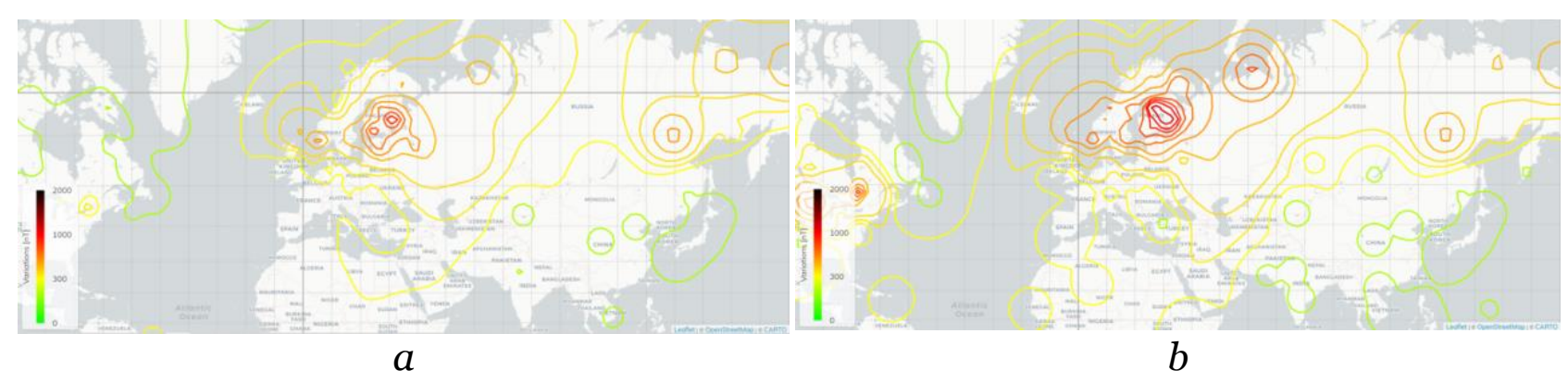




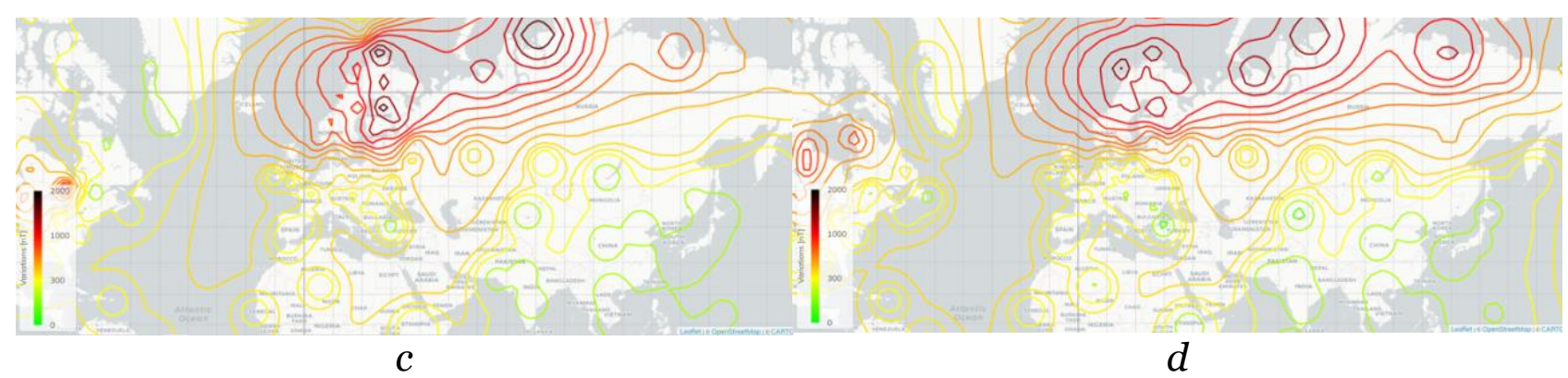

Fig. 6. Frames of dynamic visualization of the spatial distribution of the GMF disturbed component full vector during the magnetic storm on March 17, 2015: a - 23:05 UT; b 23:10 UT; c - 23:15 UT; d - 23:30 UT

The realized ability of the system to work with additional thematic layers (Fig. 7) allows identifying objects and systems that are most vulnerable in terms of extreme geomagnetic disturbances impact (high-latitude railways, power lines, etc.).

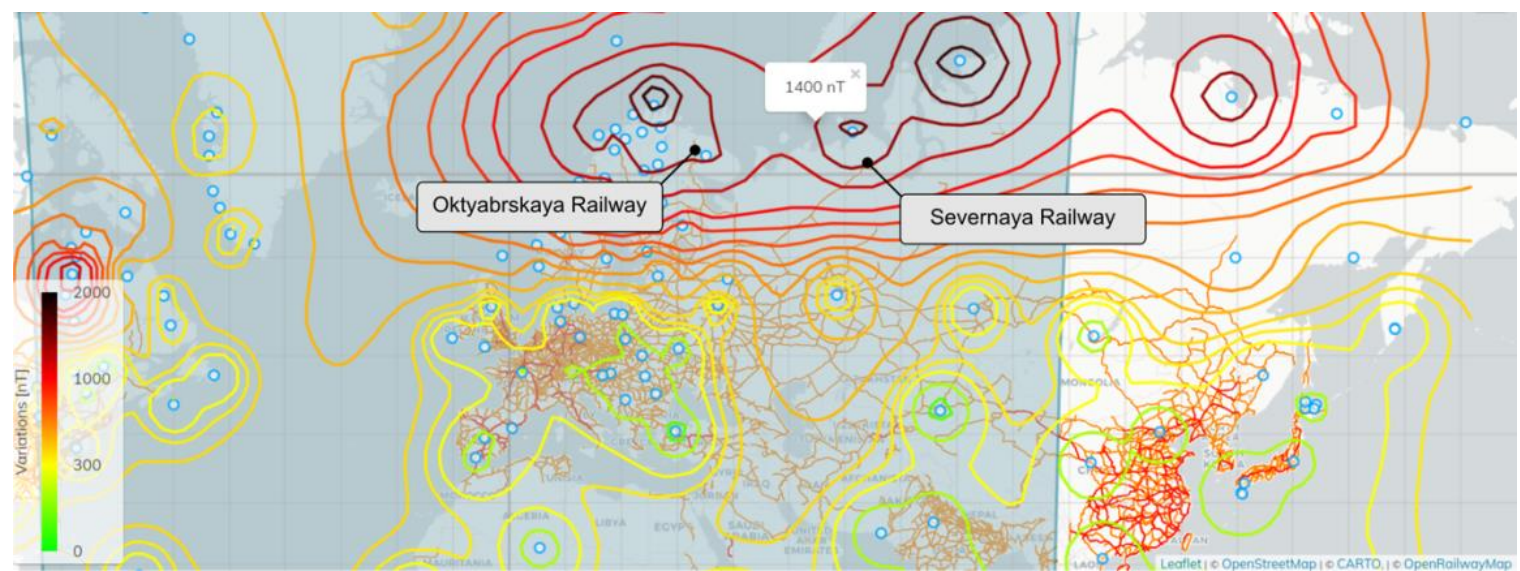

Fig. 7. Comparison of the boundaries of extreme geomagnetic disturbances and the location of technical objects in the Russian Arctic on the example of high-latitude railways (Oktyabrskaya and Severnaya railways) 2015-03-17 (23:40 UT)

The research results published in [21] indicate that the variability of the eastern component of the GMF ( $\mathrm{dE} / \mathrm{dt}$ ) has the greatest correlation with the dynamics of geoinduced currents (GIC) in the auroral zone. Comparison of the nature of the spatial distribution of this parameter with the geography of observation of extreme GIT (Sweden, northern states of the USA, the province of Quebec, Canada, the Kola Peninsula, the northern region of the Komi Republic (Russia), etc. [1-5, 7-9]) gives a basis to verify the results obtained (Fig. 8).

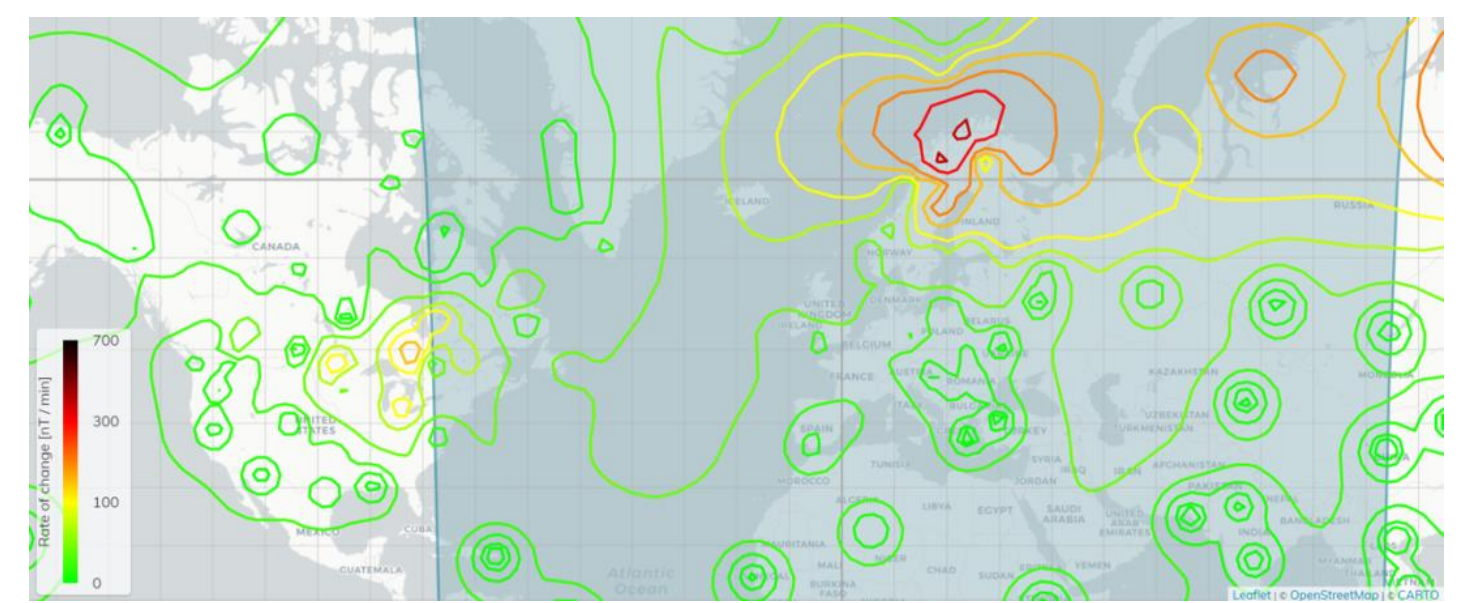

Fig. 8. The spatial distribution of the parameter $\mathrm{dE} / \mathrm{dt}$ to the date 2015-03-17 (23:15 UT) 
Thus, using the obtained results, it seems possible to define the geographical boundaries of regions with a high probability of occurrence of extreme GIT during periods of magnetic storms and substorm activity. Also, the developed system provides an estimation of a number of additional parameters, for example, such as the rate of change in the Earth's surface area $S$, within which the specified parameter of the GMF exceeds (does not exceed) the specified value $B_{0}$ :

$$
W=(d S / d t)_{\text {when } B>B_{0}}
$$

where $S$ is Earth surface area, within which the GMF parameter satisfies the condition $B>$ $B_{0} ; t$ is a time.

\section{Conclusion}

Modernization and improvement of the efficiency of existing systems for visualization, monitoring and analytical control of the parameters of the GMF and its variations in the Russian Arctic is an urgent scientific and technical problem with an acute applied character, a comprehensive solution of which can provide an increase in the level of technosphere safety in high-latitude infrastructure systems.

The paper is concerned with an approach, an architecture, a model and methods of a system for visualizing the GMF parameters in both isodynams and a vector field forms. The system uses the data of ground variation stations provided by SuperMAG and is based on the Django framework, open-source web-based GIS platforms and libraries. At the same time, the rendering of the visualized parameters, depending on the tasks to be solved and user settings, can be carried out both on the basis of a virtual globe and on the basis of traditional flat maps in dynamic or static modes.

Currently, the developed visualization system is at the beta testing stage, i.e. tested by a wide range of users in order to identify the maximum number of errors in its work and their subsequent elimination. The proposed system is available at https://geomagnetic.ru.

It is assumed that during the operation and development of the system, it will be possible to identify and predict the geographical boundaries of regions with a high probability of extreme GIT occurrence during periods of magnetic storms and substorm activity, which will allow competent individuals and organizations to make effective decisions in a timely manner and minimize the damage to the regional economy as a result of the impact of the considered natural factors.

\section{Acknowledgment}

This work was supported by a grant from the Russian Science Foundation 21-77-30010.

\section{References}

1. Kataoka R., Ngwira C. Extreme geomagnetically induced currents // Prog. in Earth and Planet. Sci., No. 3, 2016, pp. 23.

2. Danilov G.A. Povyshenie kachestva fukcionirovanija linij jelektroperedachi: [Improving the quality of operating power lines]: monograph. Moscow-Berlin, 2015. [in Russian]

3. Dobbins R.W., Schriiver K. Electrical Claims and Space Weather Measuring the visible effects of an invisible force June 2015 [Electronic resource], URL: https://static1.squarespace.com/static/57bc8a4a414fb50147550a88/t/57d84e4d1b6 31b96124f3c69/1473793614089/2015+Zurich-

Electrical+Claims+and+Space+Weather.pdf

4. Zelenyj L.M., Petrukovich A.A. Arktika. Kosmicheskaja pogoda [Arctic. Space weather] // Priroda, No. 9, 2015. P. 31-39. 
5. Kanonidi H.D., Oraevskij V.N., Belov A.V., Gajdash S.P., Lobkov V.L. Sboi v rabote zheleznodorozhnoj avtomatiki vo vremja geomagnitnyh bur' [Malfunctions of railway automation during geomagnetic storms] // Problemy prognozirovanija chrezvychajnyh situacij: sbornik materialov nauchno-prakticheskoj konferencii, 2002, P. 41- 42

6. Afanas'ev I. B., Baturin Ju. M., Belozjorskij A. G. i dr. Mirovaja pilotiruemaja kosmonavtika. Istorija. Tehnika. Ljudi [World manned astronautics. History. Technics. People.]. M.: RTSoft, 2005. 752 p.

7. Blagoveshhenskij D. V. Vlijanie geomagnitnyh bur'/subbur' na rasprostranenie kv (obzor) [Influence of geomagnetic storms / substorms on the propagation of SW] // Geomagnetizm i ajeronomija, Vol. 53, No. 4, 2013, P. 435-450

8. Klimenko M. V., Klimenko V. V., Bessarab F. S. i dr. Vlijanie geomagnitnyh bur' 2630 sentjabrja 2011 goda na ionosferu i rasprostranenie radiovoln kv-diapazona. i ionosfernye jeffekty [Influence of geomagnetic storms on September 26-30, 2011 on the ionosphere and the propagation of radio waves in the sw-range. $\mathrm{i}$ - ionospheric effects] // Geomagnetizm i ajeronomija, T. 55, No. 6, 2015, P. 769-789.

9. Gvishiani A.D., Luk'janova R.Ju. Ocenka vlijanija geomagnitnyh vozmushhenij na traektoriju naklonno-napravlennogo burenija glubokih skvazhin v Arkticheskom regione [Assessment of the impact of geomagnetic disturbances on the trajectory of directional drilling of deep wells in the Arctic region] // Fundamental'nyj bazis innovacionnyh tehnologij neftjanoj $i$ gazovoj promyshlennosti. Materialy Vserossijskoj nauchnoj konferencii, posvjashhjonnoj 30-letiju IPNG RAN, 2017, pp. 46. [in Russian]

10. Vorobev A.V., Pilipenko V.A., Enikeev T.A., Vorobeva G.R. Geoinformacionnaja sistema dlja analiza dinamiki jekstremal'nyh geomagnitnyh vozmushhenij po dannym nabljudenij nazemnyh stancij [Geoinformation system for the analysis of the dynamics of extreme geomagnetic disturbances based on observations of ground stations] // Komp'juternaja optika,, Vol. 44, no. 5, 2020, pp. 782-790. [in Russian]

11. Decree of the President of the Russian Federation of October 26, 2020 No. 645 "On the Strategy for the Development of the Arctic Zone of the Russian Federation and Ensuring National Security for the Period until 2035" [Electronic resource], URL: https://www.garant.ru/products/ipo/prime/doc/74710556/. [in Russian]

12. Vorobev A.V., Vorobeva G.R. Web-oriented 2D/3D-visualization of geomagnetic field and its variations parameters // Scientific Visualization, vol.9, 2017, pp.94-101

13. Vorobev A.V., Vorobeva G.R. Visualization of geomagnetic variations in timefrequency area of information signal // Scientific Visualization, no. 11.2, 2019, pp. 143-155, doi: 10.26583/sv.11.2.11

14. Vorobev A.V., Pilipenko V.A., Reshetnikov A.G., Vorobeva G.R., Belov M.D. Weborientirovannaja vizualizacija geofizicheskih parametrov v oblasti avroral'nogo ovala [Web-based visualization of geophysical parameters in the area of the auroral oval] // Nauchnaja vizualizacija, No. 12.3, P. 108-118, DOI: 10.26583/sv.12.3.10.

15. GOST 25645.126-85 Model' polya vnutrizemnykh istochnikov [Geomagnetic field. Model of the field of intraterrestrial sources (with Amendment No. 1)] available: http://docs.cntd.ru/document/gost-25645-126-85 (access mode: 1.03.2021)

16. Machol J. L., Green J. C., Redmon R. J., R. [et al.] Evaluation of OVATION Prime as a forecast model for visible aurora // Space Weather, no. 10, 2012, p. So3005, doi:10.1029/2011SWoo0746.

17. Gjerloev J. W. The SuperMAG data processing technique // J. Geophys. Res., No. 117, 2012, pp. A09213

18. Newell P. T., Gjerloev J. W. Evaluation of SuperMAG auroral electrojet indices as indicators of substorms and auroral power // J. Geophys. Res., no. 116, 2011, pp. A12211. 
19. Maple C. Geometric design and space planning using the marching squares and marching cube algorithms // Proc. 2003 Intl. Conf. Geometric Modeling and Graphics, 2003, pp. 90-95.

20. Vorobev A.V., Pilipenko V.A., Krasnoperov R.I., Vorobeva G.R., Lorentzen D.A. Short-term forecast of the auroral oval position on the basis of the "virtual globe" technology // Russ. J. Earth Sci., no. 20, 2020, pp. ES6001.

21. Vorobev A.V., Pilipenko V.A., Saharov Ja.A., Selivanov V.N. Statisticheskie vzaimosvjazi variacij geomagnitnogo polja, avroral'nogo jelektrodzheta i geoinducirovannyh tokov [Statistical relationships of variations in the geomagnetic field, auroral electrojet and geoinduced currents] // Solnechno-zemnaja fizika, vol.5, no.1, 2020, pp. 48-58. [in Russian] 